\title{
VALIDITY OF SIMPLIFIED ANALYSIS OF STABILITY OF CAISSON BREAKWATERS ON RUBBLE FOUNDATION EXPOSED TO IMPULSIVE LOADS
}

\author{
Lars Andersen $^{1}$, Hans Falk Burcharth ${ }^{1}$ and Thomas Lykke Andersen ${ }^{1}$
}

\begin{abstract}
Wave slamming on vertical breakwaters cause a sudden, impulsive load that may cause a caisson to slide on its foundation. Alternatively, geotechnical failure may occur in the subsoil. This paper investigates whether simple analytical solutions, accounting only for the sliding along the caisson-foundation interface, can be utilized to properly determine the deformations of the breakwater. Comparisons are made with results obtained by numerical models that include the material response of the soil. Firstly, a computational model is suggested that assumes a fully drained behavior of the subsoil. Secondly, a fully coupled dynamic pore-water-flow model is introduced. The computational examples clearly demonstrate that the deformations of the soil as well as the pore pressures must be accounted for in order to get a reliable prediction of caisson deformations during wave impact.
\end{abstract}

Keywords: caisson breakwater; wave impact; dynamic pore pressure; geotechnical failure

\section{INTRODUCTION}

\section{Presentation of the problem}

Extreme impulsive loads during impact of breaking waves on a caisson breakwater may lead to sliding of the structure or geotechnical failure in the supporting rubble foundation and seabed. The different modes of failure are illustrated in Figure 1. The actual failure mechanism in a given situation is strongly dependent on the geometry and material properties of the structure and the soil.

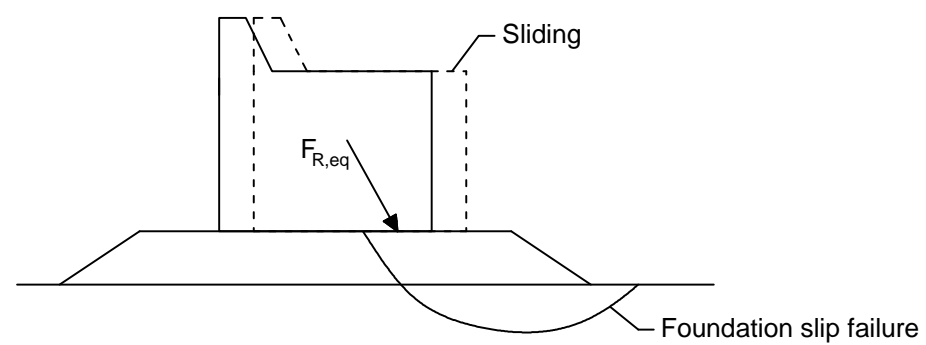

Figure 1. Failure modes for a caisson subjected to wave impact.

Burcharth et al. (2008) and others have proposed a simple model based on the one-dimensional equation of motion. As indicated by Figure 2, only the force resultants stemming from the hydraulic pressures and gravity are considered. Due to its simplicity, the model can be used for life-time analysis of a caisson; but it only accounts for sliding along the interface between the caisson and the rubble foundation. Therefore, the model is not able to account for the irreversible deformations that may develop in the foundation and the seabed, and this may lead to an underestimation of the total displacements and rotations.

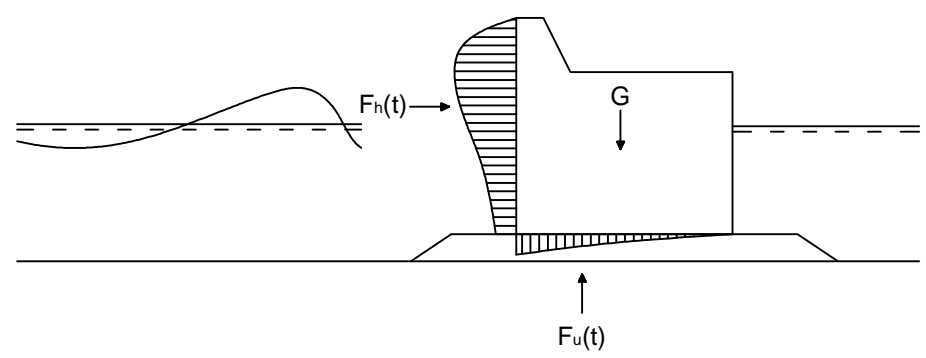

Figure 2. Dynamic part of the hydraulic pressure distribution from wave slamming on a caisson.

A model of the subsoil can be achieved by means of numerical methods. Employing nonlinear finite-element analysis, Barquín (1998) included a visco-elastic soil model. This produces a better approximation of the distribution of the contact pressure at the interface between the caisson and the foundation, but the model cannot account for failure within the soil. More realistically, plastic

\footnotetext{
${ }^{1}$ Department of Civil Engineering, Aalborg University, Sohngårdsholmsvej 57, DK-9000 Aalborg, Denmark
} 
deformations within the foundation and seabed were considered by Burcharth et al. (2009) as well as Kudella and Oumeraci (2009), again based on a finite-element approach. Recently, Hur et al. (2010) conducted a numerical study of the fluid flow near and, in particular, under a caisson breakwater on a sandy seabed, using a finite-element model coupled to a volume-of-fluid model. However, no analysis of the structural response was included in the work by Hur et al. (2010).

The present work is an extension of the research carried out by Andersen et al. (2010), who conducted a comparison of finite-element and finite-different models with the simple solution proposed by Burcharth et al. (2008). The analysis was confined to a single-phase model of the ground, in which the pore water was disregarded. In the present work, a pore pressure model is introduced in order to see the difference compared to the results obtained by the nonporous soil models.

In Figure 3, an example of a load history measured in a physical model subjected to breaking irregular waves is presented. It can be seen that the impulsive loads are very large leading to very wide caissons if a static design procedure is used. However, the largest peaks usually represent very short duration impact loads which contain little impulse to move a breakwater caisson. Therefore, the caisson width might be reduced significantly and still leading to an acceptable response of the structure with only limited sliding. However, it is necessary to quantify this by performing a dynamic analysis of the caisson and foundation under these conditions. Results of such analyses should then be used to quantify the deformations and if they are allowable or not in the relevant limit states, i.e. by considering the important storms in the entire caisson lifetime. Because of strong scale effects-especially on the response of the rubble foundation-such analysis cannot solely be based on physical model tests with a scaled caisson subjected to waves. Therefore, the foundation response has to be modeled in a computational model in which the loads are based on pressure distribution time series based, for example, on physical model test measurements.

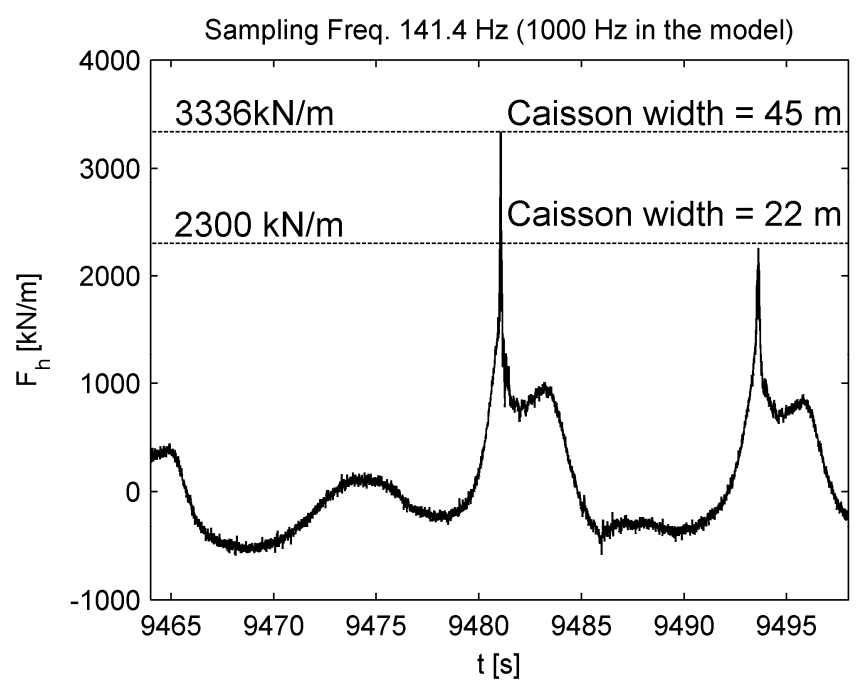

Figure 3. Horizontal force resultant from wave slamming on a caisson breakwater measured in model scale at Aalborg University. The thresholds mark the capacity of caissons with different widths in full scale.

\section{Contents of the paper}

The remaining paper consists of four parts. Firstly, the computational models applied for analysis of caisson deformation due to wave impact are discussed. Secondly, the results of a simple analytical solution are compared to those of numerical models that do not account for pore pressure built up in the rubble foundation and seabed under the caisson. Thirdly, an improved numerical model accounting for pore water flow is introduced and compared to the other solutions. Finally, conclusions are made and recommendations for further research are given. 


\section{COMPUTATIONAL MODELS FOR THE CAISSON BREAKWATER AND THE SEABED SOIL}

The analysis concerns a caisson breakwater placed on a rubble foundation over a sandy seabed. The geometry is defined in Figure 4. The wall on top of the caisson has a width of $5 \mathrm{~m}$ at the base and $2.5 \mathrm{~m}$ at the top. The seabed is assumed homogeneous to great depth.

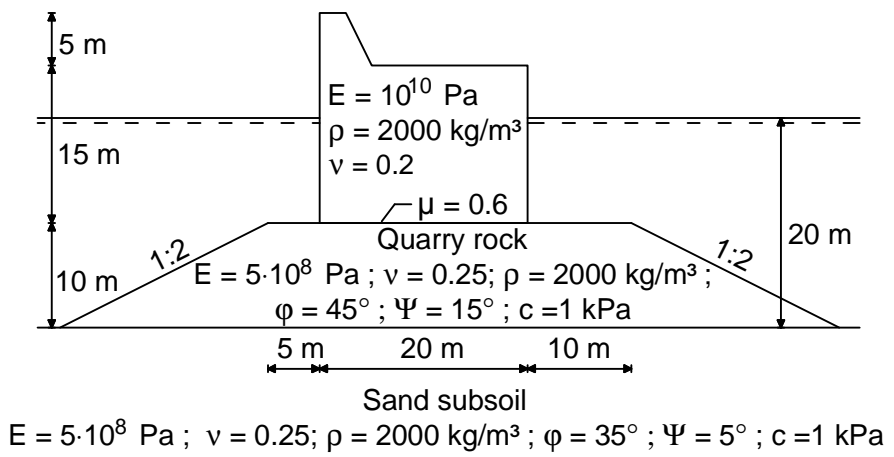

Figure 4. Geometry and material properties of the considered caisson, rubble foundation and seabed.

In order to analyze the influence of including deformation in the soil and pore water flow within the rubble foundation and seabed, five different models are compared:

- An analytical solution accounting only for sliding along the caisson-foundation interface. The caisson is simplified as a monolithic structure, and deformation of the soil is disregarded.

- Two finite-element models based on the commercial code ABAQUS (Simulia 2009). Linear and quadratic spatial interpolation is applied, respectively. A non-porous material model is applied for the caisson as well as the foundation and subsoil, i.e. the pore water is not included in the models.

- Two finite-difference models analyzed by the program FLAC ${ }^{3 \mathrm{D}}$ (Itasca 2007). Similarly to the finite-element models, a non-porous material is assumed in the first of these models. However, the second finite-difference model accounts for pore-fluid flow.

A detailed description of the models is given below. However, firstly the wave load is defined.

\section{Wave load}

As illustrated in Figure 4, a water depth of $20 \mathrm{~m}$ is assumed. However, the water and the waves are not modeled explicitly. Instead, with reference to Figures 5 and 6 , the wave force is applied as a transient pressure divided into two components: A slowly, quasi-static part denoted $P_{1}(t)$ applied on the entire front of the caisson and an impulsive load, $P_{2}(t)$. The latter only acts on the top half of the caisson front, thus modeling the wave slamming effect observed in Figure 3. Further to the buoyancy provided by the hydrostatic pressure $P_{0}$ acting on the base of the caisson, a quasi-static pressure is applied within the simpler models, i.e. the analytical solution and numerical models employing a non-porous material model of the soil. Details about the description of the hydraulic pressure at the base of the caisson in each individual model are given in the following subsections.

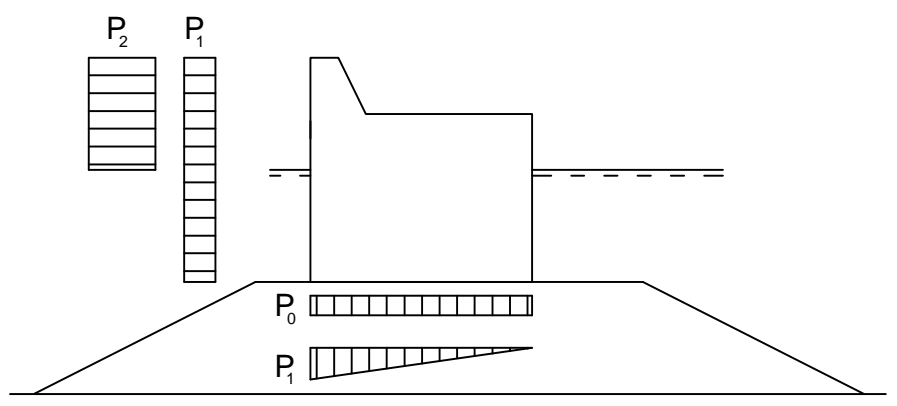

Figure 5. Simplified distribution of the hydraulic pressure on the caisson during wave slamming. 


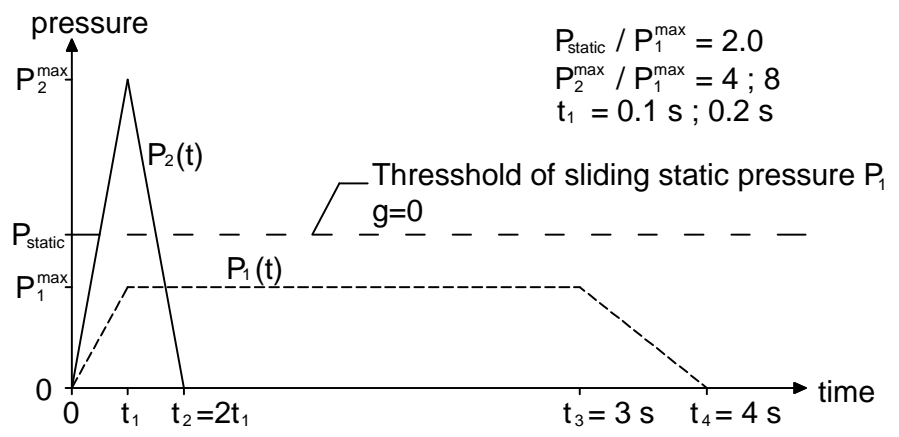

Figure 6. Time history of the two components constituting the simplified wave load on the caisson.

As depicted in Figure 6, the analysis of the caisson movement will be carried out for different combinations of the impulse duration and peak load magnitude. The maximum value of the quasi-static load, $P_{1}(t)$, is given by $P_{\text {static }} / P_{1}{ }^{\max }=2$. Here $P_{\text {static }}$ is the threshold value of $P_{1}$ leading to sliding failure in a static analysis in which the shock load $P_{2}$ has been disregarded. Based on the geometry and mass density of the caisson given in Figure 4, and employing the gravitational acceleration $g=10 \mathrm{~m} / \mathrm{s}^{2}$, the value $P_{\text {static }}=100 \mathrm{kPa}$ is determined. The density of seawater has been set to $\rho_{\text {water }}=1000 \mathrm{~kg} / \mathrm{m}^{3}$, providing a hydrostatic pressure of $P_{0}=10 \mathrm{kPa}$ at the base of the caisson at the water depth $10 \mathrm{~m}$. Further, the quasi-static pressure $P_{1}$ has a triangular distribution on the base as illustrated in Figure 5 .

\section{A simple analytical model for caisson sliding}

In order to estimate the sliding distance of the caisson breakwater, a simple analytical approach was suggested by Burcharth et al. (2008) and others. Only the force resultants in the vertical and horizontal directions are considered. These are based on the hydraulic pressures shown in Figure 5. In the present analyses, the triangular pressure distribution on the base of the caisson is assumed to act in phase with the load on the front. In reality a short delay occurs due to a finite velocity of the pressure wave travelling through the pore fluid. This effect is studied below by use of numerical models.

Sliding along the interface between the caisson and the foundation is modeled according to Coulomb's friction law. In the present case, a friction coefficient of $\mu=0.6$ is assumed (see Figure 4) corresponding to an interface friction angle of $31^{\circ}$. Sliding is calculated from the equation of motion in the horizontal direction:

$$
F(t)=F_{h}(t)-\left(G-F_{u}(t)\right) \mu=\left(M_{\text {caisson }}+M_{\text {added }}\right) \frac{d^{2} x}{d t^{2}}
$$

where $F(t)$ is the total horizontal force acting on the caisson. With reference to Figure $2, F_{h}(t)$ is the horizontal force resultant from the hydraulic pressure on the caisson front and $G$ is the gravity force on the caisson which is found from the geometry and mass density given in Figure 4 and the gravitational acceleration $g=10 \mathrm{~m} / \mathrm{s}^{2}$. Further, $F_{u}(t)$ is the vertical force resultant from the pressure on the base of the caisson. The mass of the caisson is denoted $M_{\text {caisson }}$, whereas $M_{\text {added }}$ refers to hydrodynamic (added) mass. In the present analyses, the value $M_{\text {added }}=0 \mathrm{~kg}$ has been applied in order to allow a direct comparison with the results of the numerical models, in which no added mass has been introduced.

For each event where sliding occurs, the sliding distance $\left(x_{b}-x_{a}\right)$ is found by double time integration over the time interval $t_{a}$ to $t_{b}$ :

$$
x\left(t_{b}\right)-x\left(t_{a}\right)=\frac{1}{M_{\text {caisson }}+M_{\text {added }}} \cdot \int_{t_{a}}^{t_{b}} \int_{t_{a}}^{t_{b}} F(t) d t d t
$$

Here $t_{a}$ is the instance where the stabilizing force is first time smaller than the destabilizing force and $t_{b}$ is the instance at which the velocity is again zero. During this interval, the caisson observes an acceleration phase followed by a deceleration phase.

The main advantage of this model is that it is fast and easy to use on a long time history with several important peaks. The disadvantage is that the results are less accurate than more advanced models as the model disregards rotation of the caisson and elastic/plastic deformations in the rubble foundation and the sub soil. The model is described in more detail in Burcharth et al. (2008). 


\section{Finite-element models and finite-difference models of structure-soil interaction}

As described above, two commercial codes are applied for numerical analysis of the soil-structure interaction during wave impact on the caisson, i.e. the finite-element program ABAQUS and the finitedifference solver FLAC $^{3 \mathrm{D}}$. In both models, the caisson is modeled as an impervious linear elastic isotropic material with the properties listed in Figure 4, where $E, v$ and $\rho$ are Young's modulus, Poisson's ratio and the mass density, respectively. In reality, the caisson will be constructed as a reinforced concrete shell structure divided into a number of cells filled with sand. However, in the present analyses a homogeneous model is employed with mean values of the material properties.

The foundation and the seabed are assumed to consist of quarry rock and sand, respectively. Linear elastic response is assumed below the yield limit which is provided by the Mohr-Coulomb criterion in terms of the friction angle $\varphi$ and the cohesion $c$. The plastic deformations are described by a nonassociated plastic flow model defined by the dilation angle $\psi$. Ideally, sand and quarry rock should be modeled as non-cohesive materials. However, to increase the stability of the computational methods and speed up the calculations, a cohesion of $1 \mathrm{kPa}$ is introduced in the sand as well as the rubble foundation. The influence of this artificial cohesion on the results is insignificant.

In the ABAQUS models, plane strain is assumed. Four and eight-node quadrilateral elements with linear or quadratic spatial interpolation of the displacement field are employed. As shown in Figure 7, the mesh size in the model with second-order elements is doubled compared to the mesh size in the model using linear interpolation. Hence, the nodal distance is the same in the two models. For reference, the horizontal and vertical distances between nodes in the seabed and the caisson are all $1.25 \mathrm{~m}$. The same mesh is utilized in FLAC $^{3 \mathrm{D}}$. However, here the cells are not finite elements but socalled "zones" that are used for application of body forces as well as computation of stresses and other quantities related to gradients of the displacement field and, in the porous models, the pore pressures. Standard fixities, traditionally applied in geotechnical analyses, have been used. Thus, the sides of the soil domain are fixed in the horizontal direction, whereas the base of the model is fully fixed. It has been found by numerical analyses that the artificial boundaries are placed far enough from the region of interest to ensure that no plastic strains occur near the edge. Furthermore, the reflection of energy at the boundary is insignificant in the present analyses.

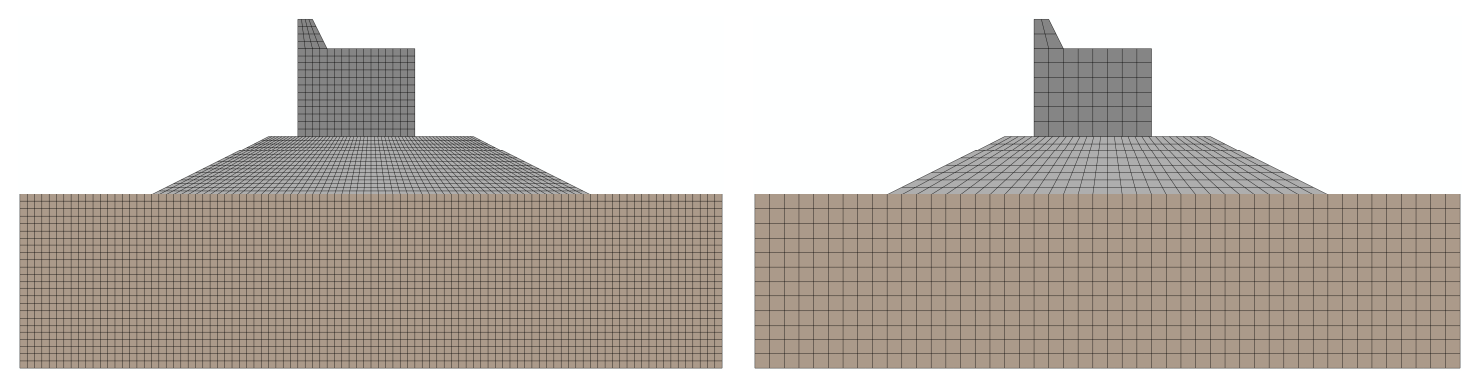

Figure 7. Geometry applied in the numerical models. Left: Finite elements with linear spatial interpolation in ABAQUS and cells used in FLAC. Right: Finite elements with quadratic spatial interpolation in ABAQUS.

Initial contact is assumed at the interface between the structure and the foundation. However, during the dynamic response slip is allowed to happen in the numerical models, i.e. the tensile strength and stiffness of the interface are both zero. In ABAQUS, a master-slave definition is employed for the interface with the top of the foundation acting as master surface and the base of the caisson acting as slave. Contact is identified when a node from the slave surface lies on or passes the element edges on the master surface. Pressure over-closure is penalized by a spring with the stiffness $10^{10} \mathrm{~N} / \mathrm{m} / \mathrm{m}^{2}$ acting in the normal direction; but no elastic deformation can occur in the tangential direction. In FLAC ${ }^{3 \mathrm{D}}$, socalled interface elements are applied at the top of the foundation. Contact is established whenever a node from another domain (in this case the caisson) hits the interface elements. Linear springs counteract penetration in the normal direction and sliding in the tangential direction. In the present analyses, the stiffness $10^{11} \mathrm{~N} / \mathrm{m} / \mathrm{m}^{2}$ has been utilized for both directions. No significant change occurs if the interface elements are instead applied on the base of the caisson or if the spring stiffness is changed by one order of magnitude.

Since the seabed and rubble foundation consist of granular materials, the in situ stresses in the soil must be established before application of the wave load. Otherwise, only the cohesion will add to the material strength. In ABAQUS, gravity is applied instantaneously and the Newton-Raphson scheme is employed to obtain static equilibrium between internal and external forces. FLAC ${ }^{3 \mathrm{D}}$ makes use of an 
explicit time-integration scheme-even in the case of a static or quasi-static load. About 100,000 time increments, called "steps", are necessary in order to get an acceptable convergence of the stresses.

In the non-porous models (ABAQUS and FLAC ${ }^{3 \mathrm{D}}$ ) a gravitational acceleration of $g=5 \mathrm{~m} / \mathrm{s}^{2}$ is applied to the seabed and foundation in order to obtain the correct effective in situ stresses within the soil skeleton prior to application of the transient load. Figure 8 shows the vertical and horizontal normal stresses at the end of gravitational loading. Full gravity is applied in the FLAC ${ }^{3 \mathrm{D}}$ models that include pore water. The porosities of sand and quarry rock have been set to 0.5 , and the effective stresses are found as the difference between the total stresses and the pore pressures. Finally, a consolidation phase is included to ensure that no excess pore pressure exists after application of gravity.
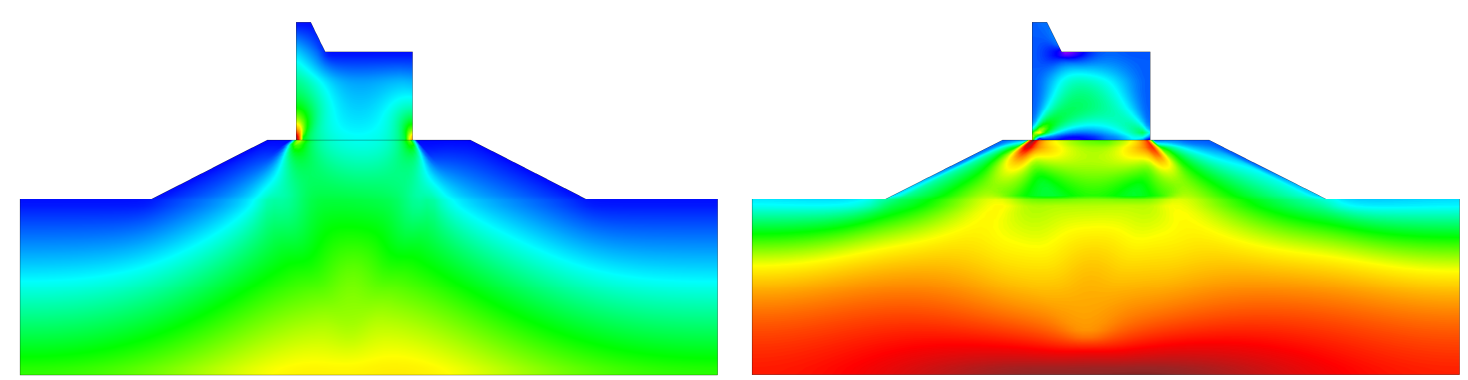

Figure 8. Total stresses at rest in the non-porous model obtained by FLAC. Left: Vertical normal stresses; the color range goes from dark brown $\left(\sigma_{z z}=-1000 \mathrm{kPa}\right)$ to blue $\left(\sigma_{z z}=0 \mathrm{MPa}\right)$. Right: Horizontal normal stresses; the color range goes from dark brown $\left(\sigma_{x x}=-200 \mathrm{kPa}\right)$ to blue $\left(\sigma_{x x}=40 \mathrm{kPa}\right)$.

The static capacity of the caisson for $P_{1}$ loading, including the soil-structure interaction, is found by ABAQUS. Figure 9 illustrates the plastic strain magnitudes at the end of the computations carried out by the models using linear and quadratic spatial interpolation, respectively. The failure modes are nearly identical and in either case a pressure of $P_{1}=98 \mathrm{kPa}$ can be applied before collapse occurs in the soil. This pressure is slightly smaller than the value $P_{\text {static }}=100 \mathrm{kPa}$ that leads to sliding of the caisson. Thus, geotechnical failure is design giving in the present case; but the two thresholds are close. A small change in geometry or material properties may cause a change from geotechnical failure into sliding.
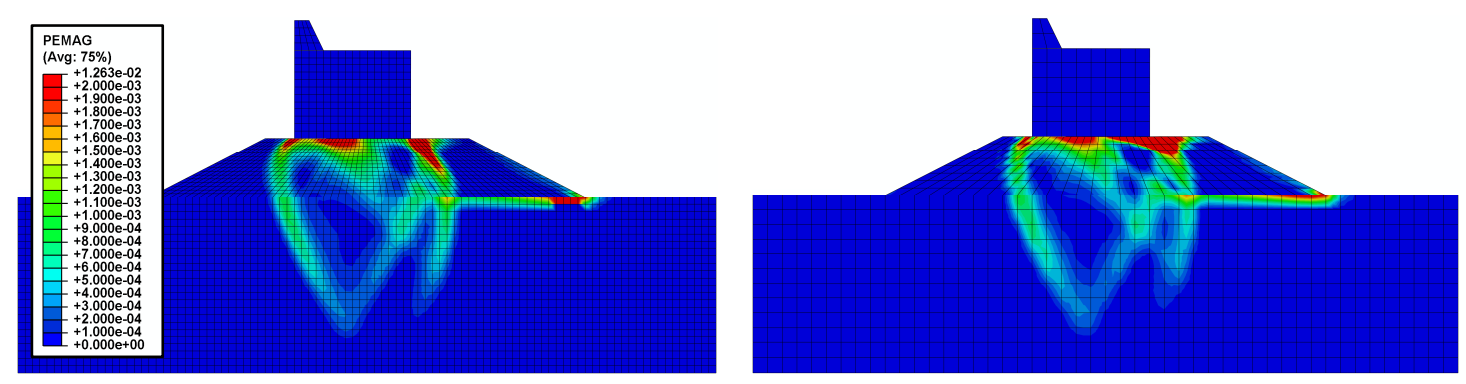

Figure 9. Failure mechanism under static loading obtained by ABAQUS. Left: Linear spatial interpolation. Right: Quadratic spatial interpolation. The color scale indicates the plastic strain magnitude.

For the dynamic analyses of the wave impact, the standard implicit time-integration scheme is applied in ABAQUS, whereas the explicit scheme is employed in FLAC $^{3 \mathrm{D}}$. The simulation of 5 seconds of real time in the non-porous models requires about 2000 increments in ABAQUS, whereas 125,000 steps are needed in FLAC ${ }^{3 \mathrm{D}}$, employing a time step of $4 \cdot 10^{-5} \mathrm{~s}$. In the models that account for pore pressure, Darcy flow is assumed since it is the only model available in $\mathrm{FLAC}^{3 \mathrm{D}}$. The hydraulic conductivity of the seabed is $k=10^{-7} \mathrm{~m} / \mathrm{s}$, which is typical for sand. Two different values are applied for the foundation: $k=10^{-4} \mathrm{~m} / \mathrm{s}$ and $k=10^{-6} \mathrm{~m} / \mathrm{s}$. These values correspond to gravel and coarse sand, respectively. The maximum time step is inverse proportional to the permeability. Hence, when the hydraulic conductivity is $10^{-4} \mathrm{~m} / \mathrm{s}$ the time step should be smaller than $10^{-7} \mathrm{~s}$ to maintain stability of the explicit scheme. Alternatively, FLAC ${ }^{3 \mathrm{D}}$ allows the use of an implicit sub-integration scheme for the pore water flow, which permits a significant increase of the time step. However, even if instability is avoided, the accuracy of the analysis is dramatically reduced when the time step is increase. In any case, a value of $k$ higher than $10^{-4} \mathrm{~m} / \mathrm{s}$ cannot be used, since it leads to very high pore-water flow velocities resulting in immediate failure of the time integration algorithm. Furthermore, Darcy flow is not realistic when the permeability is high. To account for turbulence in the flow, Forchheimer's law should be used. Ironically, this flow law is available in ABAQUS but only for the analysis of stationary flow. 
Finally, Rayleigh damping is applied, since it is available in ABAQUS as well as FLAC ${ }^{3 D}$. The damping ratio $\zeta=5 \%$ is assumed at the frequency $1 \mathrm{~Hz}$ and only mass-proportional damping is used, since the introduction of stiffness proportional damping leads to a reduction of the allowed time step. Vibrations of the caisson will be further damped by plastic response deformation the soil and viscous forces stemming from the pore water flow.

\section{RESULTS FOR A NON-POROUS SEABED AND RUBBLE FOUNDATION}

The first of the numerical analyses concerns a non-porous material model of the seabed and rubble foundation, i.e. a model without pore water flow. As suggested by Figure 4, four different combinations of the relative peak height $P_{2}{ }^{\max } / P_{1}{ }^{\max }$ and the peak width $t_{2}=2 t_{1}$ are considered.

The plastic deformation is expected to increase when the wave impact contains more energy. Thus, the combination $\left(t_{1}=0.2 \mathrm{~s} ; P_{2}{ }^{{ }^{2 a x}} / P_{1}{ }^{\max }=8\right)$ will provide greater displacements than the load defined by $\left(t_{1}=0.1 \mathrm{~s} ; P_{2}{ }^{\max } / P_{1}{ }^{\max }=4\right)$. This is clearly observed in the present analysis carried out by the analytical solution as well as ABAQUS and FLAC ${ }^{3 \mathrm{D}}$. However, as indicated by Figure 10, the plastic shear strains in the FLAC ${ }^{3 \mathrm{D}}$ model accumulate along the same slip lines within the ground, independently of the magnitude of the load. The same behavior is observed in ABAQUS using linear as well as quadratic interpolation. It is noted that the deformation at the time $2.5 \mathrm{~s}$ is much greater than the deformation at $t=0.2 \mathrm{~s}$. Hence, the main deformation mechanism develops after the passage of the impulsive load.
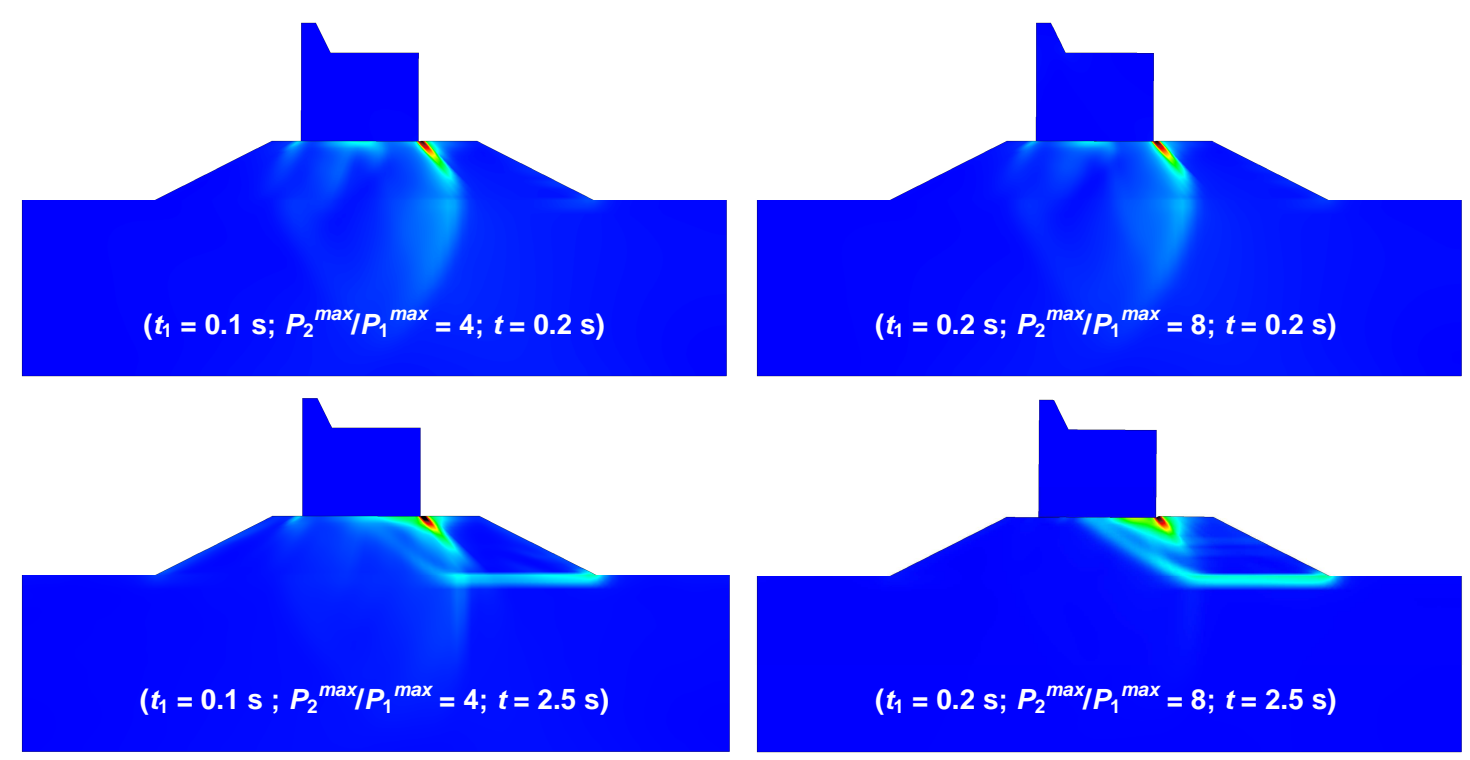

Figure 10. Deformations due to wave impact in the non-porous FLAC model at two different magnitudes of the load and two different times. Dark, red shades indicate large plastic strain magnitudes, whereas blue shades correspond to no plastic deformation.

The time histories of the horizontal displacements at the top and base of the caisson are reported in Figure 11 for the various impulsive loads. In spite of the fact that the same deformation mechanism is achieved in FLAC ${ }^{3 \mathrm{D}}$ and ABAQUS, the models do not produce the same displacements of the caisson. However, with the discretization described above the finite-difference solver FLAC ${ }^{3 \mathrm{D}}$ produces a result that is nearly identical to the results provided by the finite-elements with linear interpolation in ABAQUS. Contrarily, the finite-element analysis with quadratic spatial interpolation leads to slightly smaller displacements. This may well be due to problems arising in the contact model when quadratic interpolation is applied. A convergence study, not documented in this paper, indicates that the FLAC ${ }^{3 \mathrm{D}}$ model has a slightly better convergence rate than either of the finite-element models in ABAQUS.

A further study of Figure 11 reveals that all numerical models provide much more displacement than the analytical solution. It is expected that the displacements are greater in the numerical models since the analytical solution only accounts for sliding at the caisson-foundation interface. However, the difference is surprisingly high, since the threshold against geotechnical failure is only two percent lower than the sliding threshold in the static case. The difference is particularly huge in the case of a small impulsive load magnitude. For $P_{2}{ }^{\max } / P_{1}{ }^{\max }=4$ the analytical solution predicts a displacement which is one order of magnitude smaller than the displacements provided by the numerical analyses. At the higher load magnitudes, a better match between the analytical and numerical solutions is observed. 

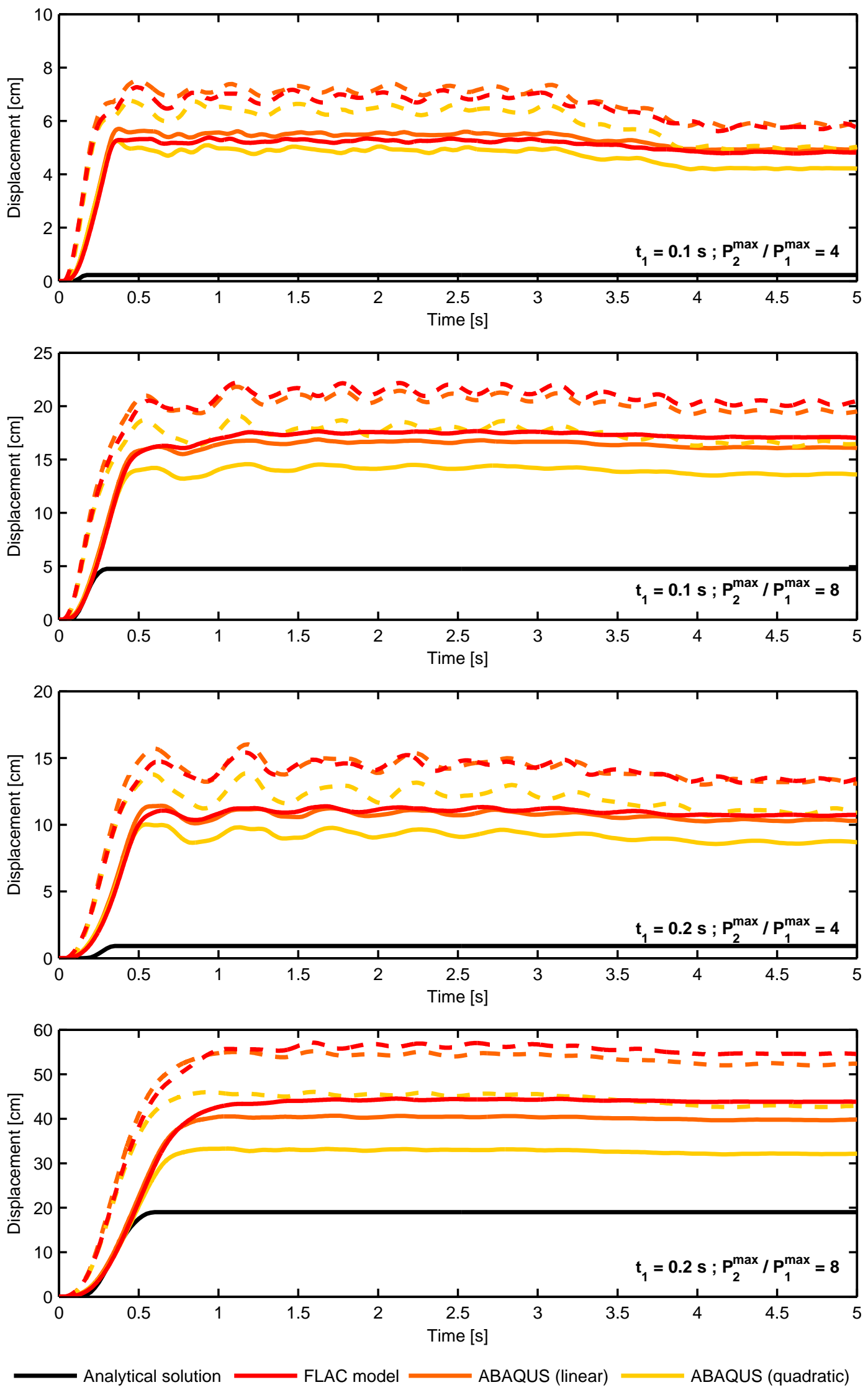

Figure 11. Displacements at the base (full drawn lines) and top (dashed lines) of the caisson front for the non-porous models analyzed by FLAC and ABAQUS. 
Finally, Figure 11 shows that the displacements at the top corner of the caisson occur rapidly after the application of the impulsive wave load, i.e. in the beginning of the simulations performed by FLAC $^{3 \mathrm{D}}$ and ABAQUS. Thus, initially the caisson rotates before it starts sliding. This effect is not modeled in the analytical solution that only accounts for sliding. In the final configuration, the horizontal displacement at the top of the caisson is only about $20 \%$ higher than the displacement at the base, and a permanent rotation smaller than 0.5 degrees is achieved. Hence, from the time histories provided in Figure 11 it may mistakenly be concluded that the caisson primarily slides along the structure-soil interface, whereas Figure 10 shows that the main part of the deformation stems from slip failure in the top of the seabed under the heel of the foundation. For a real caisson breakwater, a deformation of this kind can be misinterpreted as a simple sliding failure.

\section{INFLUENCE OF THE PERMEABILITY ON THE BREAKWATER DAMAGE}

FLAC $^{3 D}$ is applied to study the influence of pore water flow in the seabed and foundation. As previously mentioned, Darcy flow is assumed, which may be unrealistic for a highly permeable foundation where the pore water flow becomes turbulent. Again the four combinations of $P_{2}{ }^{\max } / P_{1}{ }^{\max }$ and $t_{1}$ listed in Figure 4 are analyzed. The results of the non-porous FLAC ${ }^{3 \mathrm{D}}$ model and the analytical solution are compared with the outcome of two porous FLAC $^{3 \mathrm{D}}$ models with the hydraulic conductivity $k=10^{-4} \mathrm{~m} / \mathrm{s}$ or $k=10^{-6} \mathrm{~m} / \mathrm{s}$ of the foundation material. The hydraulic pressures on the caisson are applied as total stresses in the direction normal to the surface. However, the pressure on the base of the caisson is not provided as an external load in phase with the pressure on the front of the caisson, which has been assumed in the previous computations. Instead, an additional pressure is applied on the free surface of the foundation and the seabed in front of the caisson. The value of the pressure is $P_{1}(t)$ at the caisson front. For simplicity the pressure decreases linearly to $0 \mathrm{~Pa}$ at a distance of $40 \mathrm{~m}$ away from the caisson corresponding to a quarter of a wavelength. The boundary condition is applied as a total stress as well as a pore pressure, such that the effective normal stress remains zero at the free boundary.

Figures 12 and 13 show the time histories of the pore pressures and plastic shear strains for the impulsive load defined by $\left(t_{1}=0.2 \mathrm{~s} ; P_{2}{ }^{\max } / P_{1}{ }^{\max }=8\right)$. Similar trends are observed for the loads with lesser magnitude and shorter duration. It should be noted that the caisson is modeled as a non-porous material in all the analyses. The pore pressures in the caisson are a reminiscence from the first part of the computation, in which a hydrostatic pore pressure has been defined in the entire model before application of gravity. Thus, the pore pressures in the caisson do not change during the dynamic analyses. On the other hand, the pore pressure within the foundation and the subsoil will be influenced by the boundary conditions as well as the deformation of the caisson and soil.

A clear difference is observed between the response of the model with the hydraulic conductivity $k=10^{-4} \mathrm{~m} / \mathrm{s}$ (Figure 12) and the less pervious model with hydraulic conductivity $k=10^{-6} \mathrm{~m} / \mathrm{s}$ (Figure 13). In the first of the models, the permeability of the foundation material is much higher than that of the sandy seabed, in which $k=10^{-4} \mathrm{~m} / \mathrm{s}$. Therefore, the pore water runs relatively unhindered through the quarry rock, and the conditions right beneath the caisson are close to being fully drained. However, in the sand under the toe of the foundation, a significant negative pore pressure builds up when the impulsive wave load acts on the caisson top during (see Figure 12). The excess pore pressure dissipates over time and at $t=1.0 \mathrm{~s}$ the influence of the impulsive load has diminished. At the same time, a stationary flow has evolved through the foundation.

Furthermore, Figure 12 indicates that large plastic deformations occur on the front side of the foundation during the wave impact. The increasing pore pressure on the free surface induces a rapid flux of water into the foundation. Instead of a flow deeper into the foundation and soil, the water is stored close to the surface, leading to local increase of the volume. This is a result of the relatively simplistic constitutive model applied for the soil and is not regarded as physically sound behavior. In the remaining part of the foundation, a large part of the plastic deformations occurs after the passage of the impulsive load. At $t=0.4 \mathrm{~s}$, a slip plane has formed at the foundation-seabed interface. At this stage, the deformation mechanism closely matches that of the non-porous models, cf. Figure 10. However, over the next half second, plastic deformations continue to develop, and the main part of the response takes place in a $5 \mathrm{~m}$ wide zone in the bottom half of the foundation behind the caisson. In the previous computations without the pore pressure model, this zone remains completely elastic.

When $k$ is reduced to $10^{-6} \mathrm{~m} / \mathrm{s}$, the response of the caisson and subsoil changes significantly. The pore pressure in the seabed is only weakly influenced by the impulsive load. However, a negative pore pressure arises under the toe of the caisson and a positive excess pore pressure occurs at the heel during the wave impact due to the undrained behavior. This is observed in Figure 13 at the time $t=0.1 \mathrm{~s}$. 

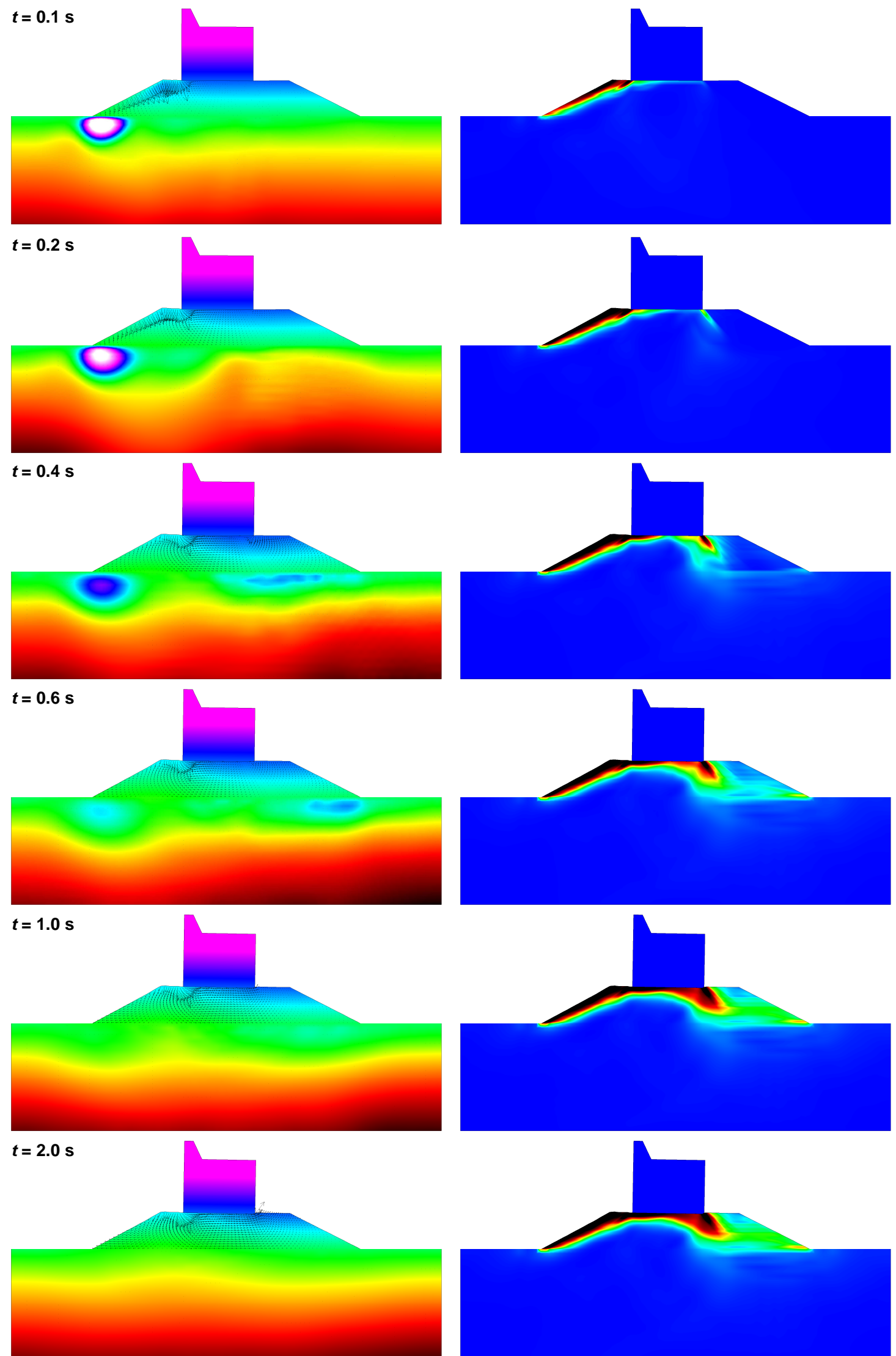

Figure 12. Results for $t_{1}=0.2 \mathrm{~s} ; P_{2}{ }^{\max } / P_{1}{ }^{\max }=8 ; k=10^{-4} \mathrm{~m} / \mathrm{s}$ Left: Pore pressures; the color range goes from magenta $(p=0 \mathrm{~Pa})$ to dark red $(p=600 \mathrm{kPa})$; white shades indicate negative pressures and arrows show the flow. Right: Plastic strain magnitude (dark red shades indicate large deformation). 

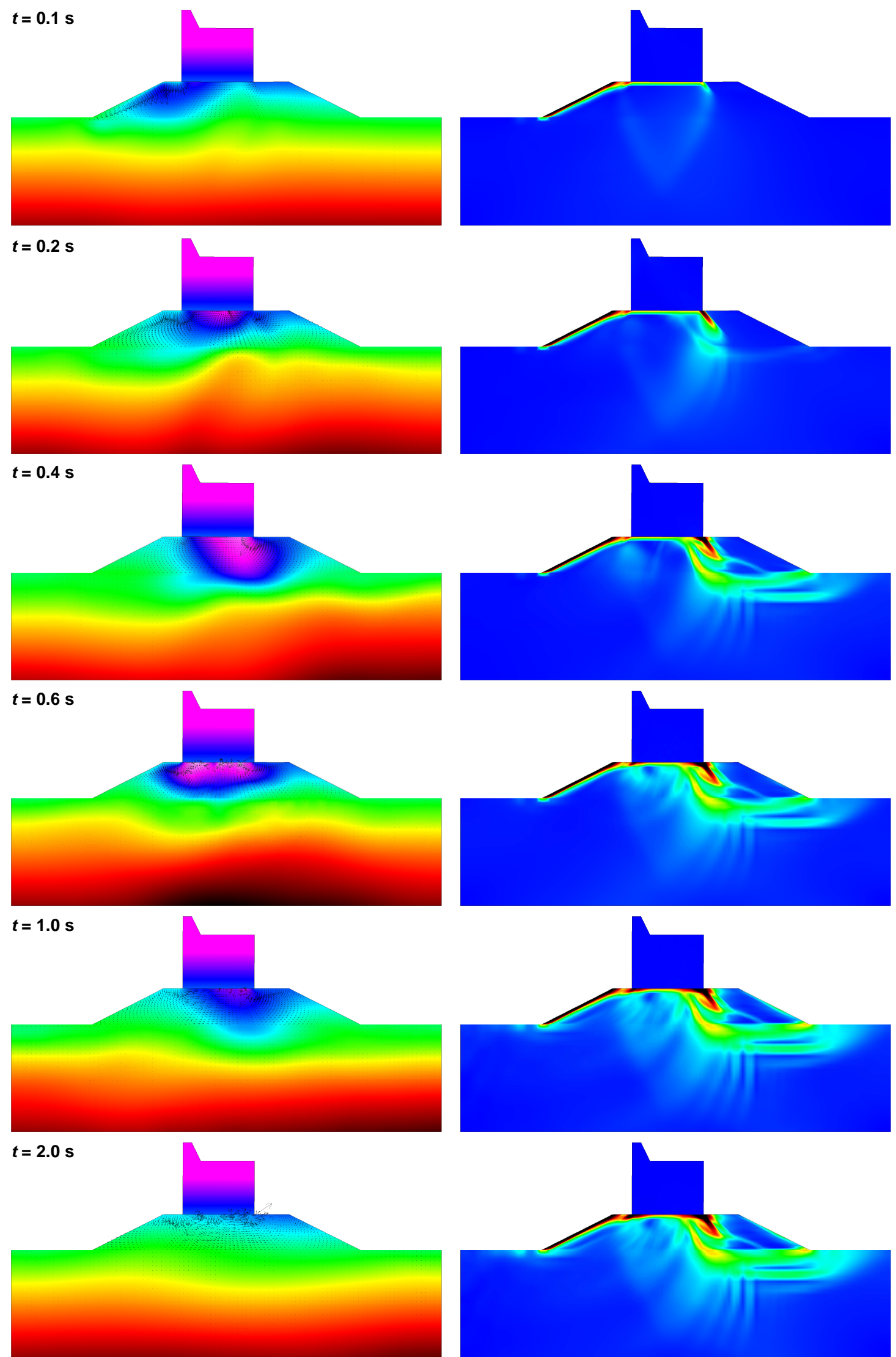

Figure 13. Results for $t_{1}=0.2 \mathrm{~s} ; P_{2}{ }^{\max } / P_{1}{ }^{\max }=8 ; k=10^{-6} \mathrm{~m} / \mathrm{s}$. Left: Pore pressures; the color range goes from magenta $(p=0 \mathrm{~Pa})$ to dark red $(p=600 \mathrm{kPa})$; white shades indicate negative pressures and arrows show the flow. Right: Plastic strain magnitude (dark red shades indicate large deformation). 

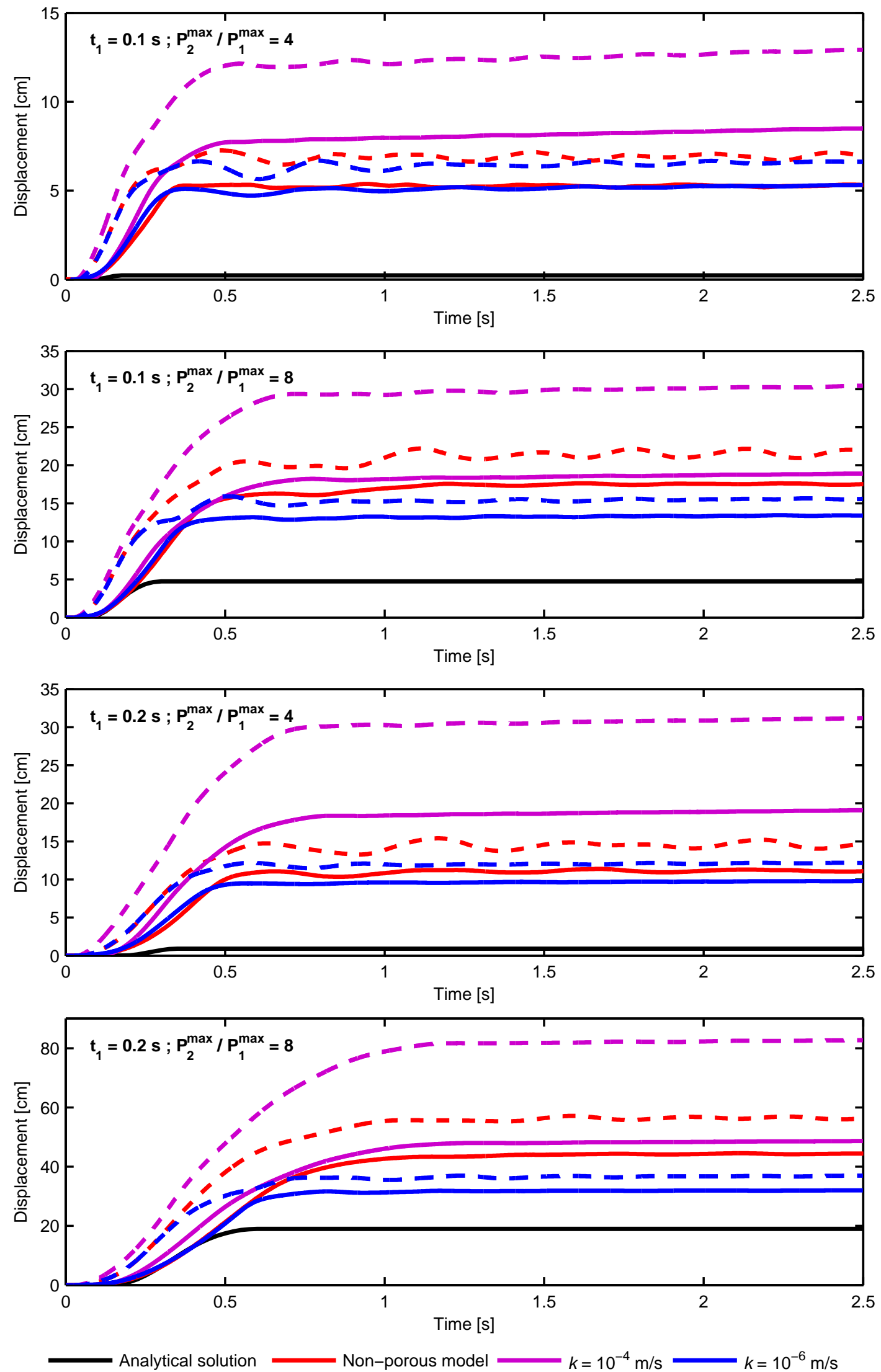

Figure 14. Displacements at the base (full drawn lines) and top (dashed lines) of the caisson front for the non-porous model and two models with different hydraulic conductivities of the rubble foundation. 
Over the next 0.3 seconds, the zone with negative pore pressures expands and moves further back under the caisson. At this stage, water is sucked in from the backside of the caisson, since this provides a shorter drainage path than flow from the front. The suction of water into the zone under the caisson continues until about $1.5 \mathrm{~s}$ after the wave impact. At the time $t=2.0 \mathrm{~s}$, the pore pressure has nearly been equalized, but a stationary flow condition has not been reached. Thus, a lot of local fluctuations in the flow directions can be observed.

Comparing the plastic shear strains in Figure 13 with those in Figure 12 it is observed that the deformations occur faster in the case with low permeability of the foundation. Thus, for $k=10^{-6} \mathrm{~m} / \mathrm{s}$ the plastic response ends at $t=0.4 \mathrm{~s}$, whereas it continues until $t=0.6 \mathrm{~s}$ when $k=10^{-4} \mathrm{~m} / \mathrm{s}$. Furthermore, the deformation mechanisms are different. For the low permeability of the foundation, the plastic zone goes deep into the seabed and no plastic deformations occur on the backside of the foundation, whereas the opposite is the case for the foundation with high permeability.

Figure 14 shows the displacements computed by FLAC $^{3 \mathrm{D}}$ for the porous and non-porous models and the four different combinations of $P_{2}{ }^{\max } / P_{1}{ }^{\max }$ and $t_{1}$. The porous model with high permeability leads to more sliding of the caisson than the non-porous model-in particular for $P_{2}{ }^{{ }^{2}} / P_{1}{ }^{\max }=4$. An increase in the rotation is also observed when the porous model with $k=10^{-4} \mathrm{~m} / \mathrm{s}$ is compared to the non-porous model. This can be explained by the gradient of the pore pressure that decreases the effective stresses and thereby the strength of the soil at the heel of the caisson. On the other hand, the model with a hydraulic conductivity of $k=10^{-6} \mathrm{~m} / \mathrm{s}$ provides a displacement that is smaller than the non-porous model for the peak height $P_{2}{ }^{\max } / P_{1}{ }^{\max }=4$. The negative pressure that develops in the pore water within the foundation with low permeability counteracts rotation. Therefore the horizontal displacement at the top corner of the caisson is only slightly greater than the displacement at the base.

It is noted that the time histories in Figure 14 have only been shown for $t \leq 2.5 \mathrm{~s}$. When the quasistatic part of the wave load is decreased linearly from $t_{3}=3 \mathrm{~s}$ to $t_{4}=4 \mathrm{~s}$, unrealistic large plastic deformations develop in the foundation in the region where the load is removed-especially in the model with high permeability. No physical explanation has been found. A possible solution may be the introduction of an improved material model. Further investigation into this matter is necessary.

\section{SUMMARY AND CONCLUSIONS}

Wave slamming on a caisson breakwater has been analyzed with focus on the deformations of the structure and the underlying foundation and seabed. This has in many previous projects been investigated by small scale physical models, but as discussed in the introduction, this is not a valid alternative to computer based simulation due to strong scale effects on especially the foundation response. Furthermore, large-scale experiments are very expensive to conduct. Therefore, the present investigations are based on numerical analyses only.

Both a simple analytical solution based on sliding of the caisson along the structure-foundation interface and finite-element and finite-difference models have been used. For the latter two approaches a non-porous elasto-plastic soil model has been used in the commercial codes ABAQUS and FLAC ${ }^{3 \mathrm{D}}$. The main results of the analyses are listed in Table 1.

Table 1. Final displacements at the base and top of the caisson obtained by the different models. For the porous models, the displacement at $t=2.5 \mathrm{~s}$ has been listed. For the remaining models, $t=5.0 \mathrm{~s}$ is used.

\begin{tabular}{|c|c|c|c|c|c|c|c|c|}
\hline & \multicolumn{4}{|c|}{$P_{2}^{\max } / P_{1}^{\max }=4$} & \multicolumn{4}{|c|}{$P_{2}^{\max } / P_{1}^{\max }=8$} \\
\hline & \multicolumn{2}{|c|}{$t_{1}=0.1 \mathrm{~s}$} & \multicolumn{2}{|c|}{$t_{1}=0.2 \mathrm{~s}$} & \multicolumn{2}{|c|}{$t_{1}=0.1 \mathrm{~s}$} & \multicolumn{2}{|c|}{$t_{1}=0.2 \mathrm{~s}$} \\
\hline & Base & Top & Base & Top & Base & Top & Base & Top \\
\hline Analytic solution & $2 \mathrm{~mm}$ & $2 \mathrm{~mm}$ & $9 \mathrm{~mm}$ & $9 \mathrm{~mm}$ & $47 \mathrm{~mm}$ & $47 \mathrm{~mm}$ & $190 \mathrm{~mm}$ & $190 \mathrm{~mm}$ \\
\hline ABAQUS (linear) & $49 \mathrm{~mm}$ & $59 \mathrm{~mm}$ & $103 \mathrm{~mm}$ & $131 \mathrm{~mm}$ & $161 \mathrm{~mm}$ & $195 \mathrm{~mm}$ & $398 \mathrm{~mm}$ & $524 \mathrm{~mm}$ \\
\hline ABAQUS (quadratic) & $42 \mathrm{~mm}$ & $50 \mathrm{~mm}$ & $87 \mathrm{~mm}$ & $109 \mathrm{~mm}$ & $136 \mathrm{~mm}$ & $165 \mathrm{~mm}$ & $322 \mathrm{~mm}$ & $429 \mathrm{~mm}$ \\
\hline FLAC (non-porous) & $48 \mathrm{~mm}$ & $58 \mathrm{~mm}$ & $107 \mathrm{~mm}$ & $134 \mathrm{~mm}$ & $170 \mathrm{~mm}$ & $205 \mathrm{~mm}$ & $438 \mathrm{~mm}$ & $546 \mathrm{~mm}$ \\
\hline $\operatorname{FLAC}\left(k=10^{-4} \mathrm{~m} / \mathrm{s}\right)$ & $85 \mathrm{~mm}$ & $129 \mathrm{~mm}$ & $191 \mathrm{~mm}$ & $312 \mathrm{~mm}$ & $189 \mathrm{~mm}$ & $305 \mathrm{~mm}$ & $487 \mathrm{~mm}$ & $827 \mathrm{~mm}$ \\
\hline $\operatorname{FLAC}\left(k=10^{-6} \mathrm{~m} / \mathrm{s}\right)$ & $53 \mathrm{~mm}$ & $66 \mathrm{~mm}$ & $98 \mathrm{~mm}$ & $122 \mathrm{~mm}$ & $134 \mathrm{~mm}$ & $156 \mathrm{~mm}$ & $320 \mathrm{~mm}$ & $370 \mathrm{~mm}$ \\
\hline
\end{tabular}

It must be emphasized that the conclusions given below are based solely on the analyses of a caisson, foundation and subsoil with the geometry and parameters provided in Figure 4 and with the wave load distribution and time histories defined in Figures 5 and 6. 
The ABAQUS and FLAC ${ }^{3 \mathrm{D}}$ models give similar results and show that the movements of a caisson exposed to impulsive loads are a combination of rocking and sliding. Rocking is the main mechanism in the beginning where the caisson observes large impulsive loads on the top part. Permanent rotations are also seen. As the simple analytical model is a one-dimensional model, it cannot predict the rocking mechanism. Moreover, the simple model does not account for elastic and plastic deformations in the foundation and subsoil. As demonstrated in Table 1, these two shortcomings lead to significantly smaller movements of the caisson in the simple analytical model compared to the more advanced models - especially for smaller displacements.

The FLAC $^{3 \mathrm{D}}$ program has been utilized for analysis of porous soil models as well, including a fully coupled dynamic pore pressure model. The model seems to provide realistic pore pressures and pore water flows in the rubble foundation and subsoil. However, the coupling with the material model provides strange results, in particular when the pulsating part of the wave load is removed. Nevertheless, this phase is of little importance as the movements have almost stabilized before this stage, and the influence on the results presented in Table 1 is negligible. A number of interesting observations can be made when the porous models are compared to the non-porous model:

- The higher hydraulic conductivity of the rubble foundation $\left(k=10^{-4} \mathrm{~m} / \mathrm{s}\right)$ provides larger displacements and larger rotation angles than both the non-porous model and the lower hydraulic conductivity $\left(k=10^{-6} \mathrm{~m} / \mathrm{s}\right)$. Presumably, this is due to the flow induced decrease of the effective strength of the soil at the heel of the caisson. The increase in the final displacements compared to the non-porous model is a factor 1.3 to 2.1 for sliding and a factor 3.1 to 4.5 for the rotation angle.

- In most cases the lower hydraulic conductivity of the rubble foundation $\left(k=10^{-4} \mathrm{~m} / \mathrm{s}\right)$ provides final displacements and rotations that are close to those achieved by the non-porous model. However, the tendency is that with increasing impact intensity the displacements become increasingly smaller than predicted by the non-porous model.

- The failure mechanism is strongly dependent on the permeability of the foundation. For a highly permeable foundation, the plastic deformations related to the displacements of the caisson are concentrated in a zone within the heel of the foundation. Contrarily, for a lower permeability of the foundation, plastic deformations occur relatively deep in the seabed.

In the present case, it is finally concluded that the simple analytical model grossly underestimates the displacements of a caisson breakwater due to wave slamming. For other geometries and material properties of the structure and subsoil, more reliable results may be achieved. A study of this will be a focus for future research. Further, to overcome some of the inaccuracies of the numerical models, improvements will be made regarding the pore water flow and the constitutive behavior of the soil.

\section{REFERENCES}

Barquín, G.G. 1998. Dynamic analysis of a vertical breakwater-extension to the Escombreras Basin Port of Cartagena, Spain, Madrid.

Burcharth, H.F., L. Andersen and T. Lykke Andersen. 2009. Analyses of stability of caisson breakwaters on rubble foundation exposed to impulsive loads, Proceedings of the $31^{\text {st }}$ International Conference on Coastal Engineering, World Scientific, 3606-3618.

Burcharth, H.F., T. Lykke Andersen and P. Meinert. 2008. The Importance of Pressure Sampling Frequency in Models for Determination of Critical Wave Loadings on Monolithic Structures, Proceedings of COPEDEC VII, Dubai, UAE.

Goda, Y. 1974. A new method of wave pressure calculation for the design of composite breakwaters, Proceedings of the $14^{\text {th }}$ International Conference on Coastal Engineering, 1702-1720.

Hur, D.-S., C.-H. Kim and J.-S. Yoon. 2010. Numerical study on the interaction among a nonlinear wave, composite breakwater and sandy seabed, Coastal Engineering, 57, 917-930.

Itasca. 2006. FLAC3D - Fast Lagrangian Analysis of Continua in 3 Dimensions - User's Guide, Itasca Consulting Group, Inc., Minneapolis, Minnesota USA.

Kudella, M. and H. Oumeraci. 2009. Experimental and numerical study of the response of a sandbed beneath a caisson breakwater subject to cyclic wave load, Proceedings of the $31^{\text {st }}$ International Conference on Coastal Engineering, World Scientific, 3619-3631.

Simulia. 2009. ABAQUS Version 6.9 Documentation, Dassault Systèmes Simulia Corp., Providence, RI, USA.

Takahashi, S., K. Tanimoto and K. Shimosako. 1994. A proposal of impulsive pressure coefficient for the design of composite breakwaters, Proceedings of the International Conference on HydroTechnical Engineering for Port and Harbour Construction, Yokosuka, Japan, 438-457. 